\title{
Editorial
}

\section{La cuestión del socialismo}

L

os artículos que presentamos en este número son expresión de un renovado esfuerzo intelectual para reflexionar alternativas a la actual configuración capitalista que solucionen realmente los graves problemas que aquejan a la humanidad, sobre todo de las mayorías empobrecidas.

Frente al descalabro del socialismo "real" y bajo la hegemonfa de la ideología neoliberal, se hace hoy necesario repensar nuevos proyectos que posibiliten nuevas formas humanas de convivencia que superen la negatividad del presente capitalista a nivel mundial.

El estado de pobreza de la mayoría de la humanidad, la creciente desigualdad y la destrucción ecológica provocada por los procesos y pautas de producción, distribución y consumo dentro del sistema capitalista, cuestionan el proclamado éxito y la pretendida superioridad del mismo.

A pesar de lo que proclaman los ideológos neoconservadores y neoliberales, no podemos resolver los problemas fácticos aceptando pasivamente y confiando en que las fuerzas ciegas del mercado nos darán por sí solas el mejor mundo posible. Por ello, más que cobijarnos en las modas de pensamiento y entregarnos ingenuamente en los tentáculos de un superficial liberalismo, tenemos que volver a los hechos y reflexionar creativamente por abrir nuevos horizontes teóricos para pensar en la liberación de la humanidad en el actual momento histórico.

Es esto lo que nos lleva a poner de nuevo en el tapete de la discusión la cuestión del socialismo como alternativa al capitalismo. En esta línea las preguntas que los autores de los artículos tratan de responder buscan dilucidar esa cuestion: ¿Qué queda del socialismo? ¿Es posible pensar un modelo teórico de socialismo viable y deseable? ¿Sigue siendo válido el socialismo como alter- 
nativa al capitalismo? ¿Cuáles serían sus líneas básicas y sus elementos conformadores? Obviamente son preguntas difíciles de contestar, sobre todo en un contexto intelectual que proclama el viejo argumento de que el socialismo no puede funcionar, ahora más fortalecido con los acontecimientos de Europa del Este y de la ex-Unión Soviética.

Sin embargo, ahora que la hegemonía capitalista parece más firme y la izquierda aparece sin norte y necesitada de una visión alternativa, los materiales para construir una alternativa socialista y defenderla están más a la mano. Como dice D. Schweickart, la izquierda está ahora en condiciones de argumentar con confianza moral y cientifica, que existe una forma deseable de socialismo que funcionará.

De acuerdo a A. González, dos hechos fundamentales son los que estarfa permitiendo en la coyuntura actual pensar y diseñar un proyecto nuevo de socialismo: el derrumbe del socialismo de origen soviético y los límites internos del capitalismo.

El "fracaso del socialismo" es en realidad el fracaso de un. proyecto muy concreto diseñado en la era estaliniana que buscaba construir el socialismo mediante un sistema estatal de planificación centralizada. Es este sistema y sus fallas intrínsecas las que terminaron ocasionando su hundimiento. La burocracia, la ineficiencia y el totalitarismo no fueron simples "errores" humanos, sino elementos constitutivos del sistema soviético y que a la postre permitieron que el capitalismo acabara absorbiéndolo.

El hecho fue que, mientras la lógica interna del capitalismo conducía a una incesante innovación tecnológica y a una expansión mundial del sistema, la lógica interna del socialismo soviético no favorecía esencialmente la innovación tecnológica, y sus tendencias expansivas no eran comparables a la dinámica mundializadora propia del capitalismo (más motivadas por razones ideológicas y políticas que económicas).

El fracaso del socialismo de origen soviético es paralela al fracaso de las estrategias socialdemócratas para asegurar la liberación humana. Ambos tienen en común la afirmación, poco marxista, de que el Estado nacional sería capaz de llevar a cabo una auténtica emancipación humana. Si la socialdemocracia asignaboba esta tarea al estado burgués, el socialismo de talante soviético insistía en la necesidad de crear un Estado proletario dirigido por su "vanguardia". El centro y eje de la liberación se ponía en el Estado. Ahora, frente a la globalización capitalista que se impone derribando todos los obstáculos que se oponen a sus dinamismos expansivos intrínsecos, cualquier transformación del Estado nacional resulta insuficiente.

En relación a los límites internos del capitalismo, los hechos muestran que el capitalismo está chocando con sus propios límites antes de realizar su prometida 
abundancia a través del respeto a las reglas del mercado. Pues bien, estos límites son los límites ecológicos del planeta. El capitalismo, por su lógica interna, es un sistema intrínsecamente abocado hacia el crecimiento y a la expansión. Su tendencia hacia la innovación tecnológica y hacia el desarrollo de las fuerzas productivas termina chocando con los límites ecológicos del planeta. Esto está llevando a un consenso cada vez mayor por poner límites a la dinámica interna del mercado capitalista. Límites que no los puede poner cada capitalista particular, pues éste se encuentra presionado por el mercado. Tampoco lo pueden hacer los Estados nacionales de forma aislada, pues cada uno de ellos tiene que asegurar la supervivencia de sus empresas capitalistas. Ahora se ve como necesario un control global del sistema como único método para frenar la lógica destructiva del capitalismo.

Los límites ecológicos del planeta muestran las fronteras del capitalismo como sistema mundial, pero también la imposibilidad de un desarrollo ilimitado de las fuerzas productivas que haga desaparecer definitivamente la escasez. Esto hace que cualquier nuevo proyecto socialista no sólo debe incluir en su agenda los problemas ecológicos, sino que también debe contar necesariamente con la escasez y, por tanto, con alguna forma de mercado.

Estos dos hechos, pues, crean las condiciones para pensar en una nueva estrategia socialista para solucionar los problemas globales de la humanidad. Una nueva estrategia que, superando las insuficiencias del socialismo "soviético" y de la socialdemocracia, busque ser una alternativa al sistema capitalista, eliminando la pobreza y frenando la destrucción ecológica del planeta. 